\title{
Circulating Clonotypic B-Cell
}

National Cancer Institute

\section{Source}

National Cancer Institute. Circulating Clonotypic B-Cell. NCI Thesaurus. Code C120462.

A B-lymphocyte that is hyperdiploid, has clonotypic Ig H gene rearrangements, and is found in the peripheral blood of patients with monoclonal gammopathy of undetermined significance or multiple myeloma. 